Fi el d Di st $r i$ but $i$ on of a Fl ux-Concent $r$ at $i$ on Type Li near I nducti on Not or

\begin{tabular}{|l|l|}
\hline 著者 & $\begin{array}{l}\text { Roy D. , Fuj i yoshi A., Yamada Sot oshi, I wahar a } \\
\text { Nasay oshi }\end{array}$ \\
\hline $\begin{array}{l}\text { j our nal or } \\
\text { publ i cat i on t i t l e }\end{array}$ & I EEE Tr ansact i ons on Nagget i cs \\
\hline vol une & 37 \\
\hline number & 4 \\
\hline page r ange & $2841-2843$ \\
\hline year & $2001-07-01$ \\
\hline URL & ht t p: //hdl . handl e. net /2297/48310 \\
\hline
\end{tabular}




\title{
Field Distribution of a Flux-Concentration Type Linear Induction Motor
}

\author{
D. Roy, A. Fujiyoshi, S. Yamada, Member, IEEE, and M. Iwahara, Member, IEEE
}

\begin{abstract}
This paper has reported the eddy current and secondary-core flux density distributions of a flux-concentration type linear induction motor (FCLIM) based on the effect of flux-concentration by eddy currents. In the developed FCLIM, the slot leakage flux is reduced and as a result more flux is concentrated into the air gap. Thrust characteristics are also determined using the parameters of the equivalent circuit. It is observed from the calculated and experimental results that the developed FCLIM has better performance than that of the normal type tubular LIM.
\end{abstract}

Index Terms-Eddy current, field distribution, fluxconcentration, leakage flux, linear induction motor.

\section{INTRODUCTION}

A FLUX concentration type linear induction motor, which has better performance than normal tubular LIM, has been developed in our laboratory and has already been reported [1]. In the case of normal tubular LIM, due to the higher value of leakage reactance, the air gap flux is decreased. On the other hand, in the case of FCLIM, the leakage flux is reduced. The conducting plate inserted between the exciting coils in each slot is the key element of the FCLIM. The eddy currents induced in the conducting plate create a counter mmf which opposes the passage of the slot leakage flux. Thus the leakage reactance of the linear motor is decreased and more flux is concentrated into the air gap, resulting in an increase of the developed thrust. Recently, another FCLIM of smaller size than the previous model has been developed. In our earlier model, the stator of the FCLIM is fixed and the mover pipe can move. In our present model, the stator can move over the secondary rail and this model is more effective for the applications like transport of materials, product distribution systems etc. This paper presents the eddy current and secondary-core flux density distributions of the smaller size FCLIM. The secondary-core flux density distribution along the motor length is better for the FCLIM than that of the normal type tubular LIM. It is observed from the calculated results using equivalent circuit parameters and the experimental results that the FCLIM has better thrust-characteristics compared to that of normal type tubular LIM.

\section{CONSTRUCtional FEATURES}

Fig. I shows the fabricated set-up of a flux-concentration type 4-pole LIM, which has an annular-linear configuration. The

Manuscript received October 13, 2000.

The authors are with the Faculty of Engineering, Kanazawa University, Kanazawa 920-8667, Japan (e-mail: roy@magstar.ec.t.kanazawa-u.ac.jp).

Publisher Item Identifier S 0018-9464(01)07091-1.

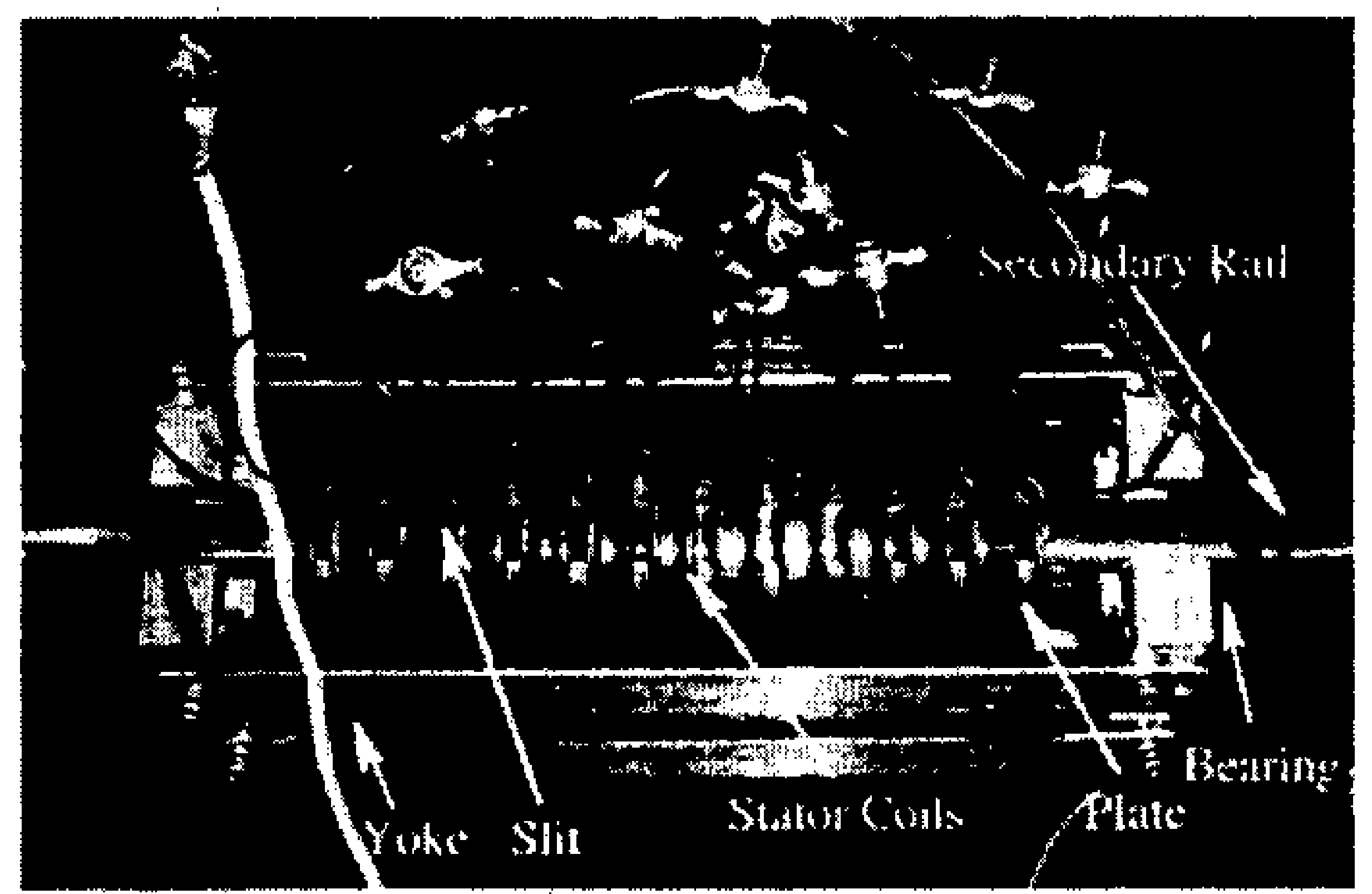

Fig. 1. Fabricated set-up of FCLIM.

construction is very rugged. The conducting plate, along with the exciting coil of 38 turns, is inserted in each of the 12 slots. The conducting plate has an air hole in its center and a slit in the radial direction. The cross-section of the conducting plate is T-shaped. The slit forces the eddy currents to flow around the air hole. Five yokes made of laminated silicon steel are arranged radially. The length and outer diameter of the stator are $224 \mathrm{~mm}$ and $126 \mathrm{~mm}$ respectively. The width of stator tooth is $8 \mathrm{~mm}$ and the width of stator slot is $10 \mathrm{~mm}$. The pole pitch is $54 \mathrm{~mm}$. The width of the slit is $15.4 \mathrm{~mm}$. The outer diameter and thickness of the copper tube is $30 \mathrm{~mm}$ and $1 \mathrm{~mm}$ respectively. The thickness of the plate is $5 \mathrm{~mm}$. The stator can move over the copper tube inside of which there is iron core.

\section{Finite ELEMENT ANALYSIS}

In order to obtain the magnetic flux density and eddy current density distributions finite element analysis is performed using the 3D field simulator [2]. The analysis is performed on one fundamental unit consisting of two coils, one conducting plate in between the coils, the corresponding segments of the yokes, copper tube and the iron core as shown in Fig. 2. The number of elements are 288852 when plate is used and 182573 when plate is not used. Figs. 3 and 4 show the flux density distributions under the standstill condition along the line $A A^{\prime}$ through the center of the slot as shown in Fig. 2 for the normal type tubular LIM and for the FCLIM respectively. The values of the flux densities are higher for the FCLIM than those for normal type tubular LIM. Fig. 5 shows the current density distribution under the standstill condition along the line $A A^{\prime}$ when plate is used. 

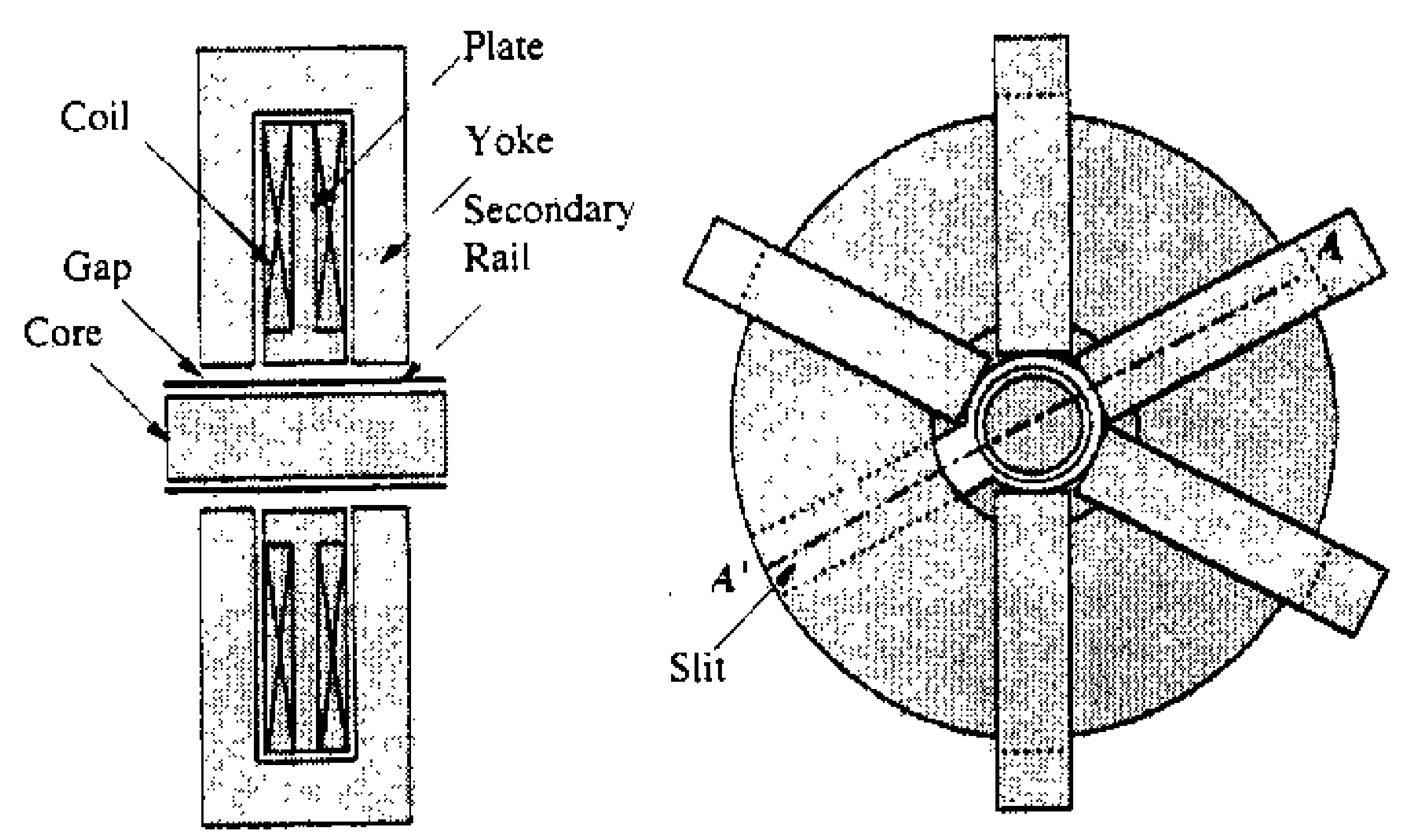

Fig. 2. Model used for finite element analysis.

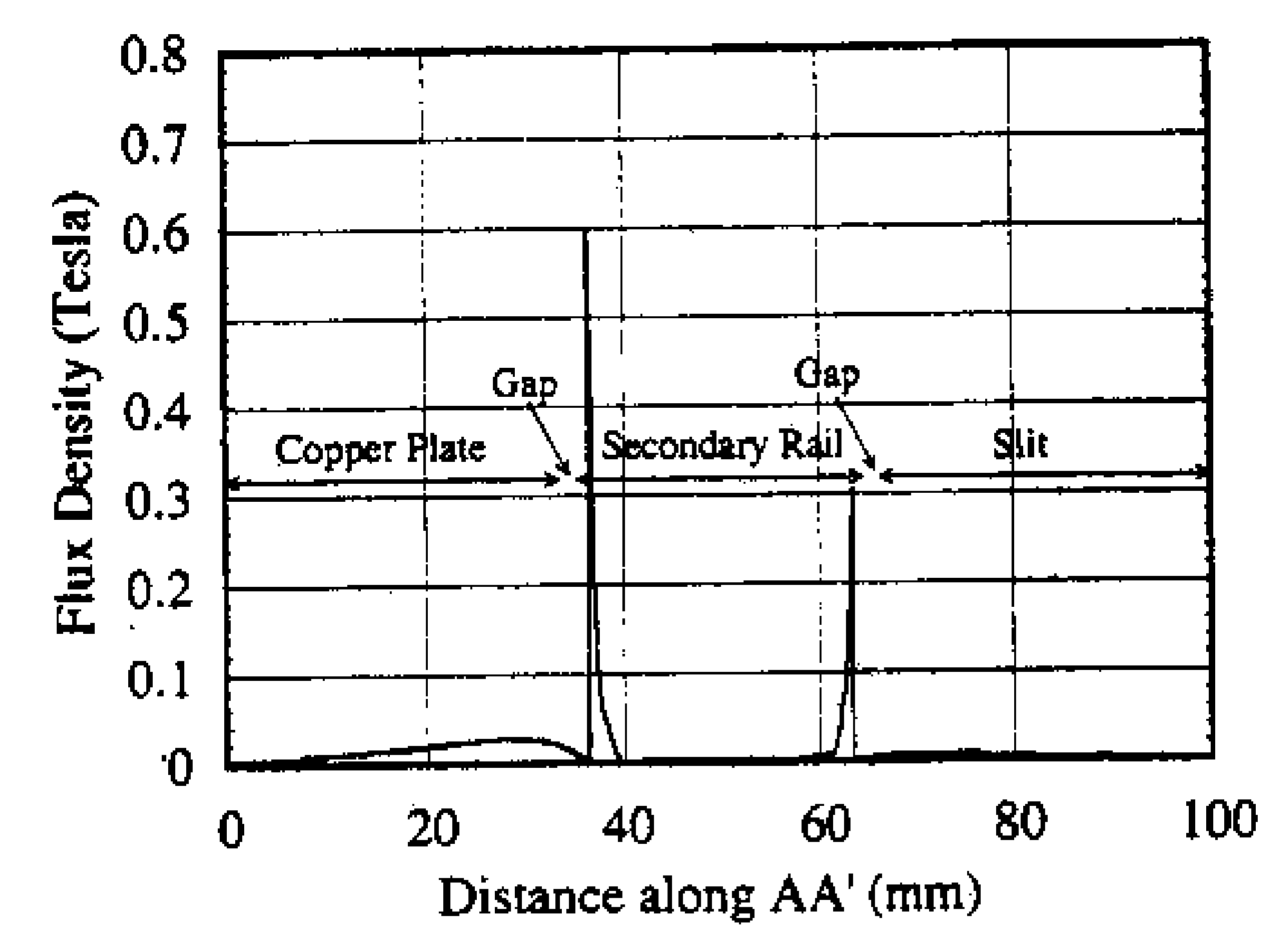

Fig. 3. Flux density distribution along $A A^{\prime}$ for normal tubular LIM.

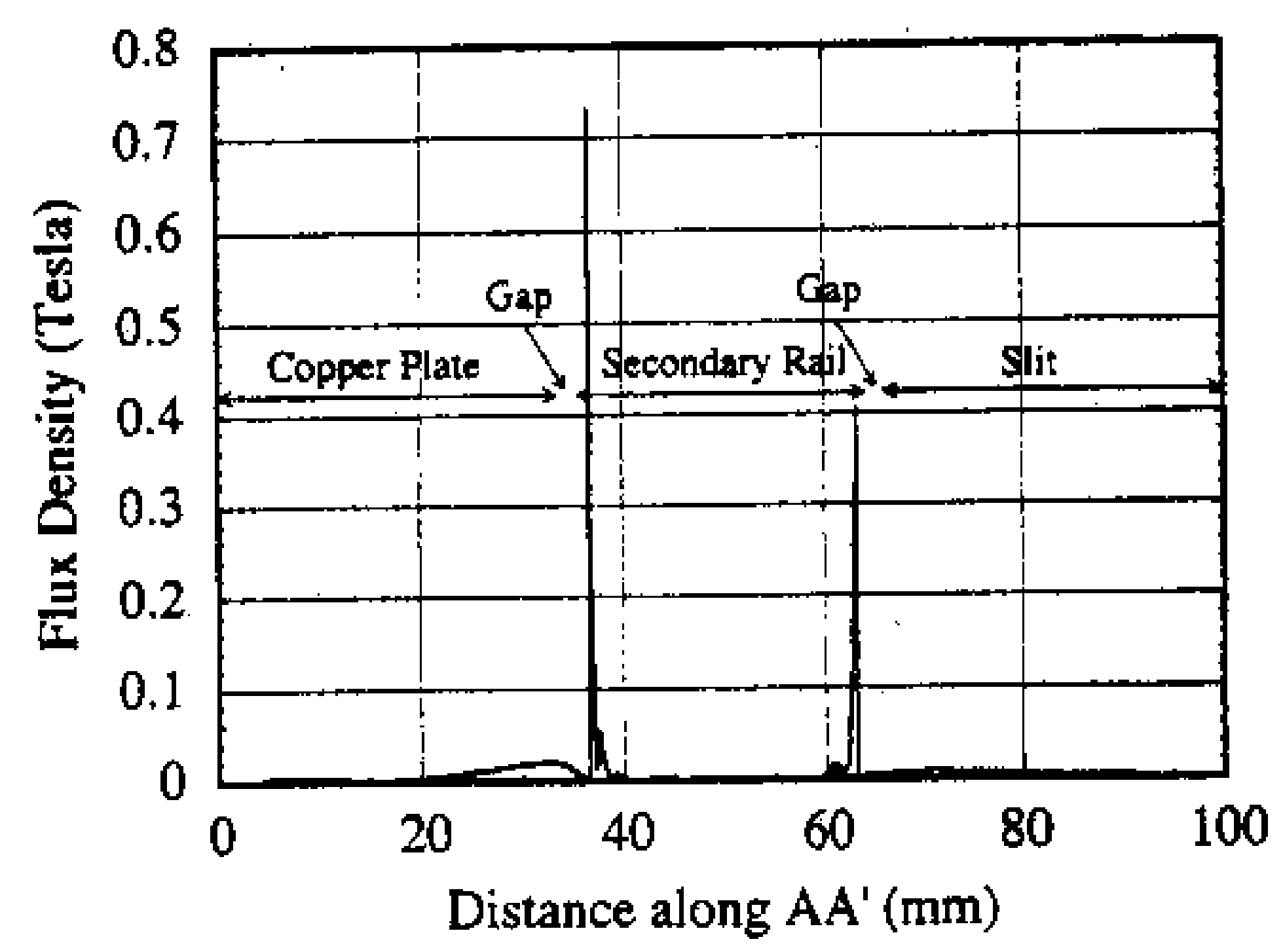

Fig. 4. Flux density distribution along $A A^{\prime}$ for FCLIM.

\section{Performance PREDICTION Using EQUIVALENT CiRCUIT PARAMETERS}

Fig. 6 shows the per phase equivalent circuit of LIM [3]. Here, $x_{m}, r_{0}, r_{1}$ and $x_{1}, r_{2}^{\prime}$ and $x_{2}^{\prime}$ are the magnetizing reactance, core loss resistance, stator resistance and leakage reactance, $\mathrm{sec}-$ ondary resistance and leakage reactance referred to stator respectively. In the presence of a plate between the stator coils in each slot, the value of the stator leakage reactance is decreased by a factor $K$ given by [4]

$K=$

$\underline{(\operatorname{Sinh} 2 \alpha d-\operatorname{Sin} 2 \alpha d)+2(\operatorname{Sin} \alpha d \cdot \operatorname{Cosh} \alpha d-\operatorname{Sinh} \alpha d \cdot \operatorname{Cos} \alpha d)}$ $\alpha d \cdot(\operatorname{Cosh} 2 \alpha d-\operatorname{Cos} 2 \alpha d)$

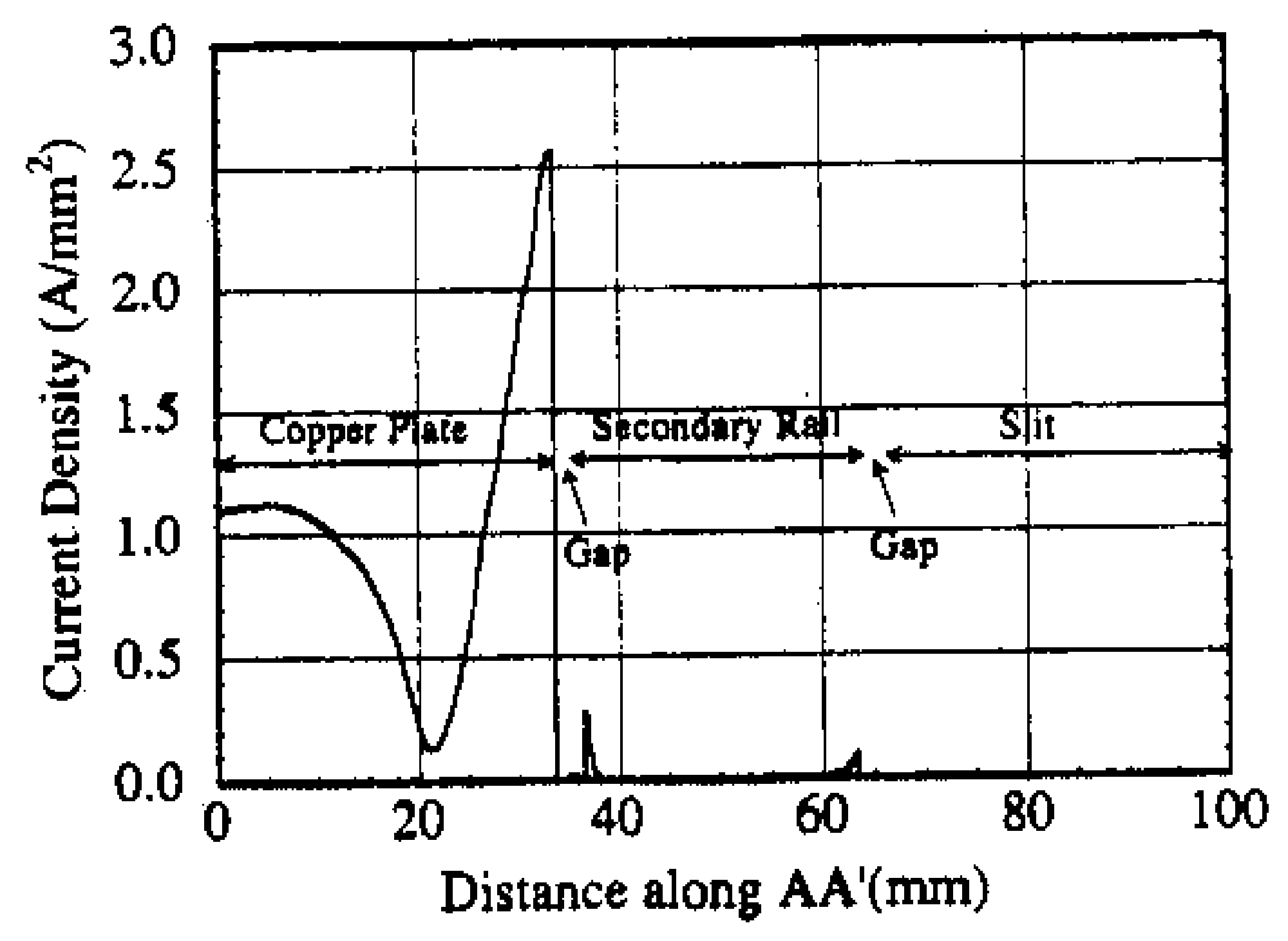

Fig. 5. Current density distribution in the presence of plate.

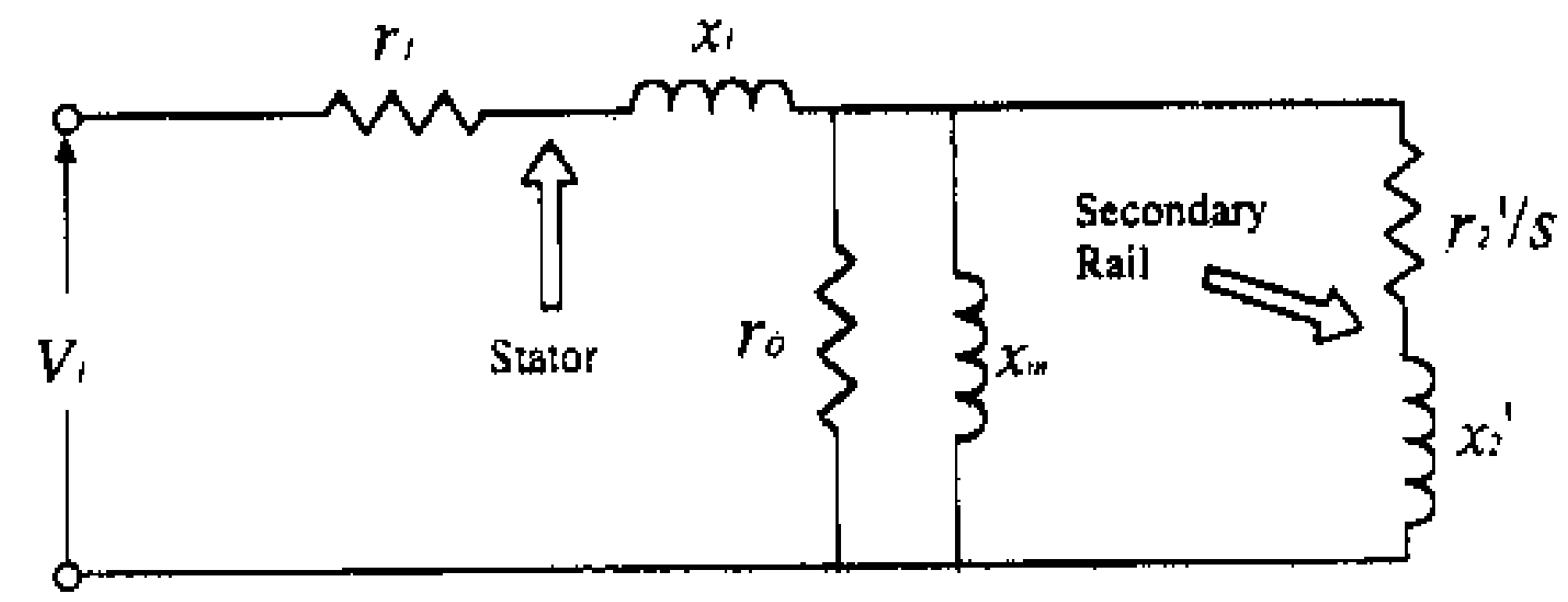

Fig. 6. Equivalent circuit of LIM.

where, $\alpha d$ is the effective depth of the plate.

$\alpha d$ is given by

$$
\alpha d=1.06 d \sqrt{r f / 60}
$$

where,

$d$, in is the depth of the plate placed under the stator

$\mathrm{cm}$, conductors,

$r \quad$ is the ratio of the effective plate width to the slot width and

$f \quad$ is the supply frequency.

After obtaining the equivalent circuit parameters the force calculations are done using equation (3)

$$
F=\frac{3 I_{2}^{\prime 2}\left(r_{2}^{\prime} / s\right)}{2 \tau f}
$$

where,

$F \quad$ is the developed thrust force,

$\tau \quad$ is the pole pitch,

$s \quad$ is the slip,

$r_{2}^{\prime}$ is the secondary resistance per phase referred to stator and

$I_{2}^{\prime} \quad$ is the secondary current per phase referred to stator.

\section{EXPERIMENTAL RESULTS}

The secondary-core magnetic flux density distribution has been measured by search coils wound around the rail under each slot. Fig. 7 shows the secondary-core flux density distributions along the motor length under standstill condition at $60 \mathrm{~Hz}$ and $120 \mathrm{~Hz}$ respectively. At the entry end the magnetic field is weakened by the entry end effect, the field is built up gradually and there are sharp rises on the distribution curves near the exit end. All the curves have been measured with the same stator current 


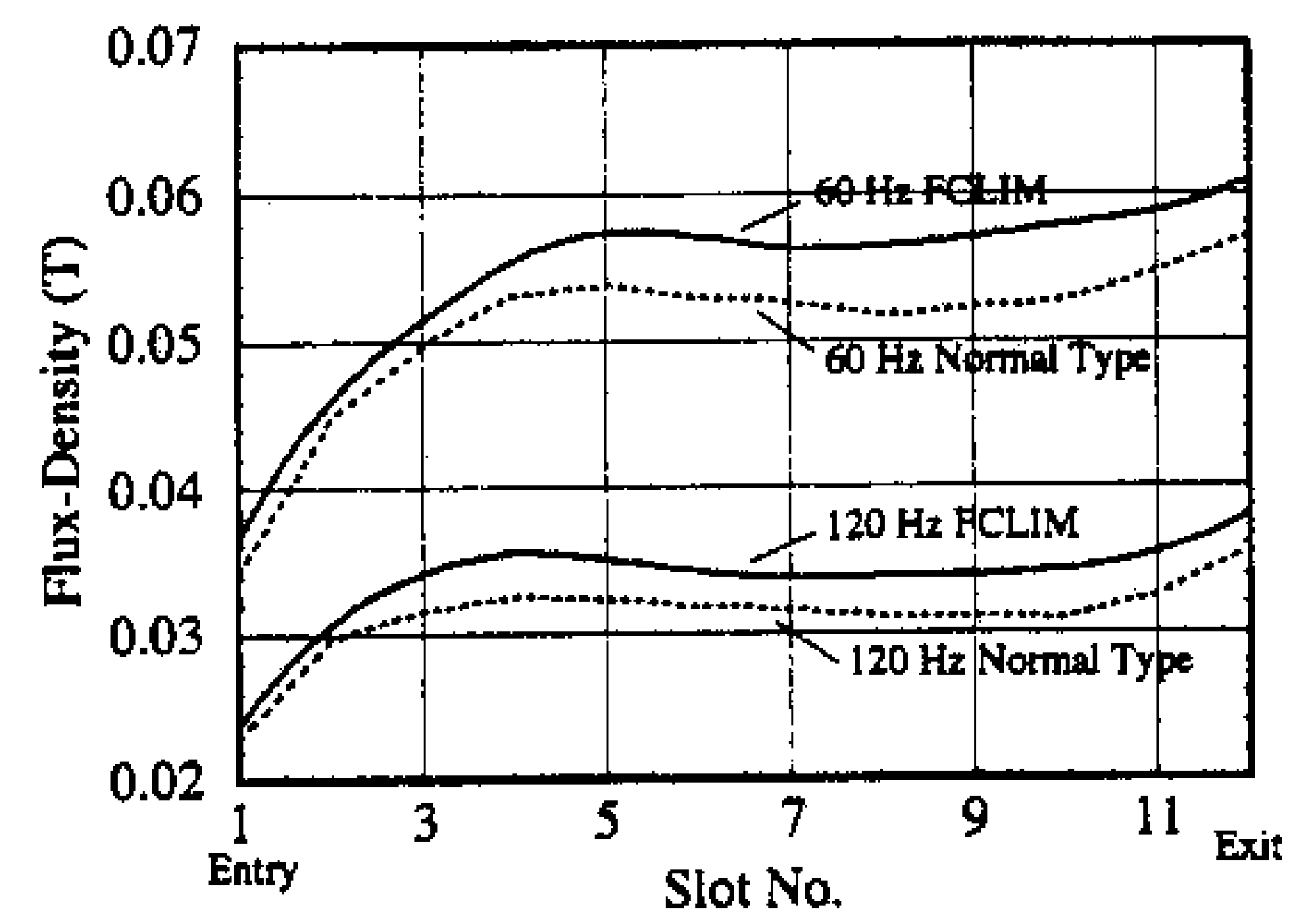

Fig. 7. Secondary-core flux density distribution.

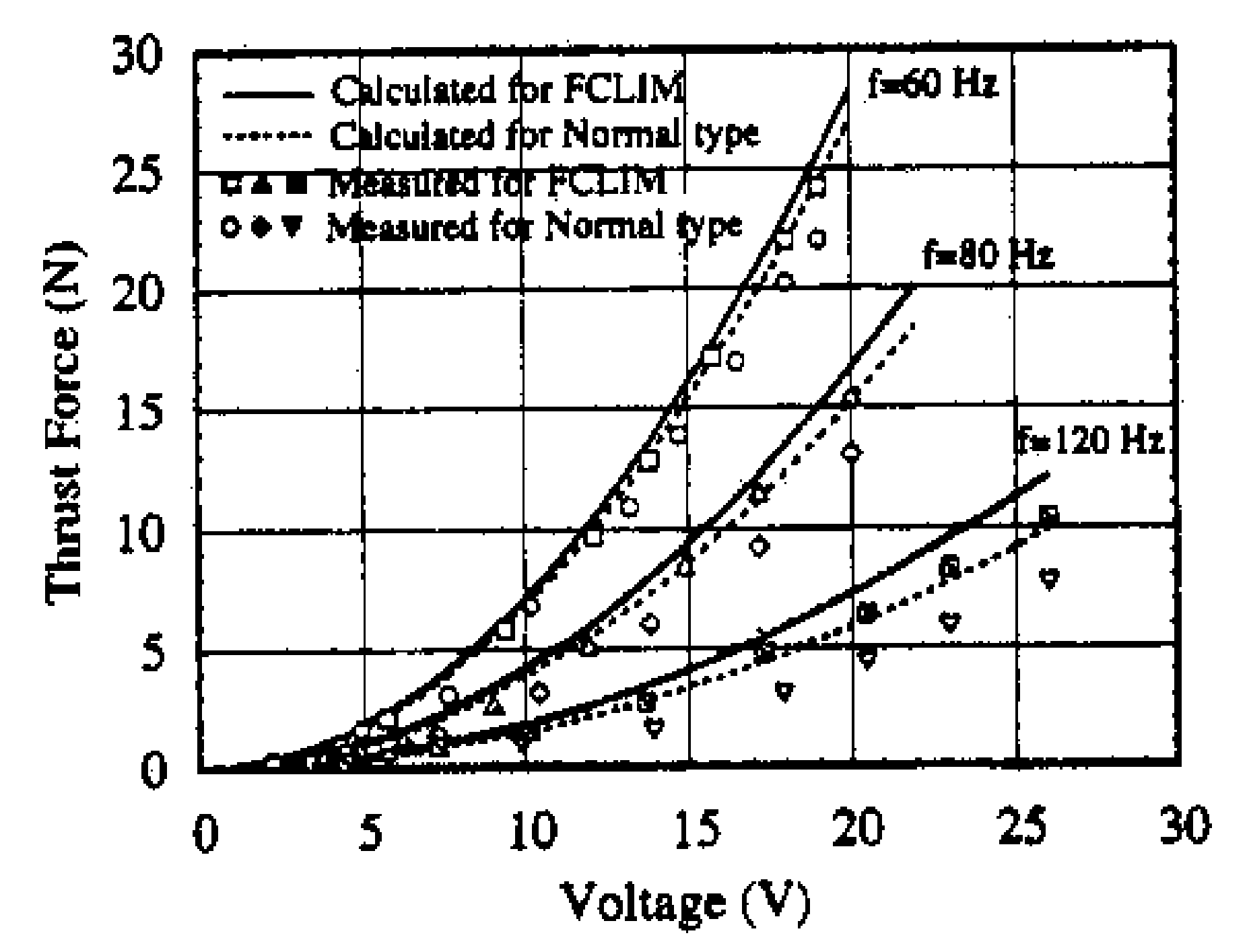

Fig. 8. Standstill thrust versus voltage characteristics.

of $5 \mathrm{~A}$. The values of flux densities for FCLIM are higher than those for normal type tubular LIM.

Fig. 8 shows the standstill thrust versus voltage characteristics of the FCLIM and those of normal tubular LIM at $60 \mathrm{~Hz}$, $80 \mathrm{~Hz}$ and $120 \mathrm{~Hz}$ respectively. The design frequency is $60 \mathrm{~Hz}$. The $80 \mathrm{~Hz}$ and $120 \mathrm{~Hz}$ characteristics are shown to understand that the effect of the plate is pronounced at higher frequencies. The input voltage is adjusted by using a three-phase voltage regulator and the frequency is adjusted by using a PWM inverter. Thrust has been measured with the help of a load cell.

Fig. 9 shows the calculated thrust versus slip and thrust versus efficiency characteristics of the FCLIM and those of normal type tubular LIM at a stator input voltage of $22 \mathrm{~V}$ and at a stator

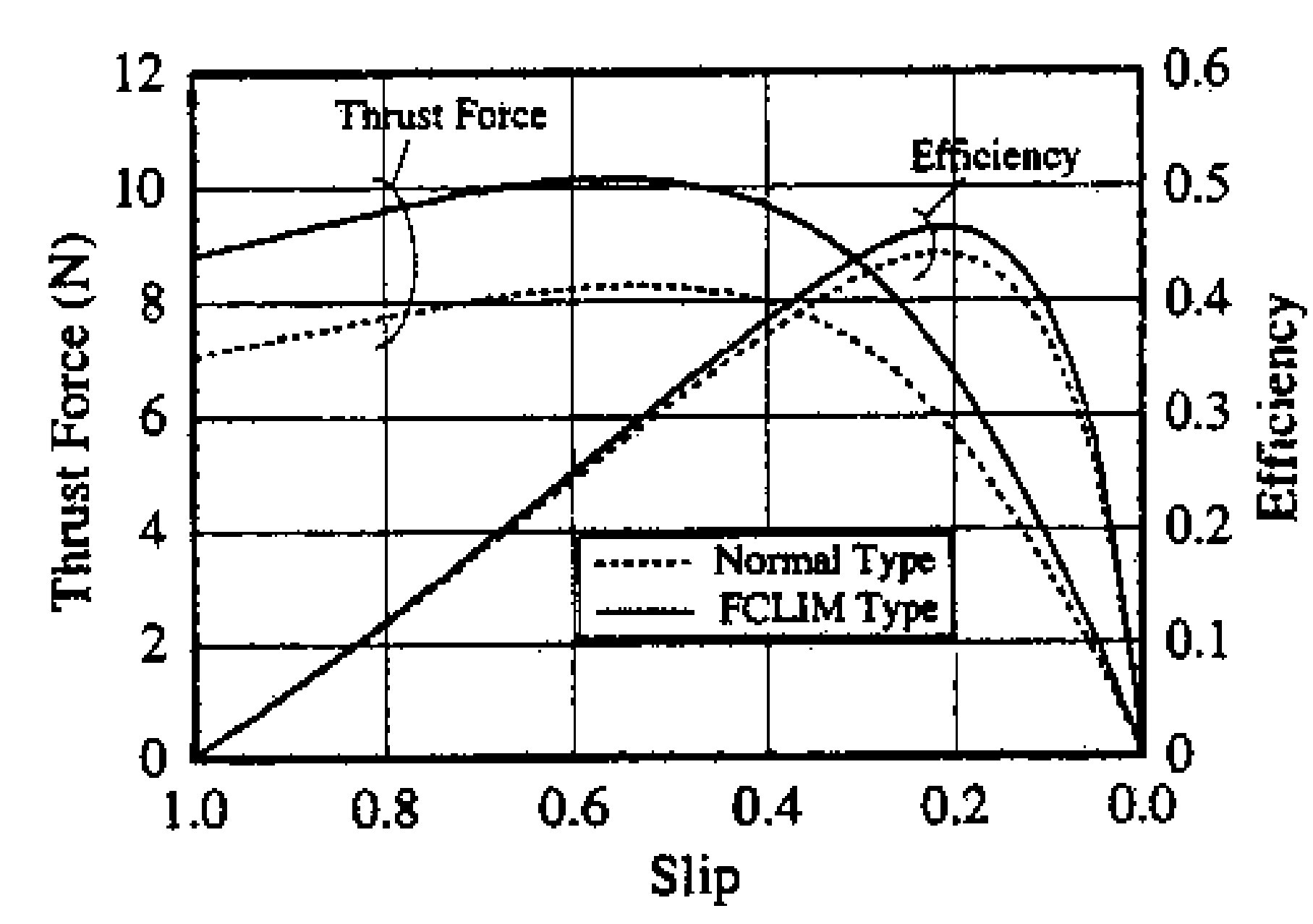

Fig. 9. Thrust versus slip and efficiency versus slip characteristics.

supply frequency of $120 \mathrm{~Hz}$. The thrust forces are calculated neglecting the end effects and the magnetic asymmetry due to the sectionalized stator core. It is observed that the starting thrust and the thrust for lower speed applications are more in the case of FCLIM than those of normal type tubular LIM. The normal range of operation of the developed FCLIM in terms of slip is 0.3 to 1 . Some losses are occurred in the plate, however, the overall efficiency of the FCLIM improves due to the more effective flux.

\section{CONCLUSTONS}

This paper has presented the field distribution and the performance of a flux-concentration type LIM. Due to the flux-concentration effect by eddy currents the secondary-core flux density distribution along the motor length is better for the FCLIM than that of the normal type tubular LIM. In FCLIM the leakage flux is reduced considerably and the air gap flux is increased. The FCLIM is suitable for short linear motion and lower speed applications.

\section{REFERENCES}

[1] D. Roy, D. Saruhashi, S. Yamada, and M. Iwahara, "Fabrication and development of a novel flux-concentration type linear induction motor," IEEE Trans. Magn., Sept. 2000, submitted for publication.

[2] Ansoft Corporation, "Maxwell 3D Field Simulator, Version 5.".

[3] V. V. Vadher and I. R. Smith, "Perfomance of a segmented rotor tubular linear induction motor," IEEE Trans. Magn., vol. 29, no. 6, pp. 2941-2943, Nov. 1993.

[4] P. L. Alger, Induction Machines, 2nd ed. New York, NY: Gordon and Breach. Science Publishers, 1970, pp. 272-277. 